\title{
Ecological Response Characteristics of Interconnected River System Network in Karst Area: A Case Study of Dabang River Basin Connecting Engineering in Guizhou Province
}

\author{
Li Liang ${ }^{1,}{ }^{*}$, Zuoqin Guo ${ }^{2}$, Huixia Y ang ${ }^{2}$, Hexi Zhang ${ }^{1}$, Wei Huang ${ }^{1}$ \\ ${ }^{1}$ G uizhou W ater Resources Research Institute, Guiyang 550002, China \\ ${ }^{2}$ Civil Engineering College, Guizhou University, Guiyang 550025, China
}

\begin{abstract}
As an important water control strategy in the 21st century, interconnected river system network has been widely implemented in all parts of China. However, the possible ecological response mechanism which can be decided by the structure of rivers and the river-lake connectivity is still in the exploratory stage at present, especially in karst areas where the ecosystem is particularly fragile. Taking the Huangguoshu Waterfall-Wangerhe reservoir connection engineering in Dabang River Basin of Guizhou Province as an example, this paper collects the basic data of hydrometeorology, vegetation coverage and river water quality in the Dabang River Basin in the past 20 years, and study and analysis the connectivity of water system and the ecological factors based on GIS which include meteorological, terrestrial habitat and water environment before and after the completion of the Link Project. The results show that the implementation of the project not only changes the connectivity pattern of river and lake systems, but also has a significant impact on the hydrometeorology, terrestrial habitat and water environment. The increase of connectivity leads to the decrease of regional rainfall, evaporation and temperature year by year, while the vegetation coverage and water temperature show an annual upward trend. In addition, the water quality of the receiving area is better after the implementation of the river-lake link project, which does not bring water pollution risk to the receiving area.
\end{abstract}

\section{Introduction}

At the beginning of the 21st century, our country put forward the water control strategy of connecting rivers and lakes to solve the water problems, such as shortage of water resources, lower allocation capacity of water resources, lower utilization ratio of water resources water pollution et ${ }^{[1]}$. As the key of inland water cycle, river and lake system is an important component of ecological Environment. In recent years, with the development of ecological civilization in China, many local governments have begun to work on the management and restoration of ecologically fragile rivers, estuaries, lakes and wetlands, comprehensively planned the layout of water resources, and carried out a series of connection projects of river and lake system ${ }^{[2]}$.

In general, increasing connectivity of river-lake system can effectively improve the vertical connectivity of the river-lake system, enhance the water cycle power, accelerate the water exchange and improve the hydrodynamic conditions, contribute to forming a dynamic water network, and enhancing the water self-purification capacity ${ }^{[3]}$. At the same time, it also can enhance the lateral connection between river and floodplain, and effectively repair the floodplain-wetland system $^{[4]}$. At present, the research of the connectivity of water system started late in China, and be still in an exploratory stage. Many research methods and index systems to solve the non-linear problems in river ecosystem, the impact of ecological scheduling and the river health caused by the connectivity of water system are still no uniform standard ${ }^{[5]}$.

The increasingly severe rock desertification phenomenon in the karst area is obvious, with poor water and soil conservation capacity and fragile and sensitive ecological environment ${ }^{[6]}$. The connected river-lake systems form a dynamic water system network, which will more or less affect the longitudinal hydrological recharge and drainage law in karst area ${ }^{[7]}$. To date, several studies involving the impact of increasing water system connectivity on the water ecological environment have been conducted, but few of these studies mention the response relationship between water system connectivity and ecological environment in karst area. Therefore, it is important to carry out the research on the impact of river-lake water system connectivity on the ecological environment in karst areas and master the response mechanism between the connectivity of water system and the ecological environment.

Taking the Huangguoshu Waterfall-Wangerhe 
reservoir connection engineering in Dabang River Basin of Guizhou Province as an example, this paper explore and analysis the evolution characteristics and laws of ecological environment and connectivity of water system in karst area by collects the basic data of hydro-meteorology, vegetation coverage and river water quality in the Dabang River Basin in the past 20 years.

\section{Study area}

In order to regulate the water volume in Huangguoshu Waterfall scenic spo in the dry season, Wanger River
Reservoir in the Dabang River Basin was officially impounded in November 2004, and the river water was led to the upstream of the waterfall through a diversion channel (the project location is shown in Figure 1). The water volume of about $400000 \mathrm{~m}^{3}$ per day can be supplied to Huangguoshu waterfall, which is enough to maintain a spectacular scene of Huangguoshu waterfall in the four seasons. The purpose of water system connection project is to improve the landscape in the dry season, which is of great significance to the local economic development

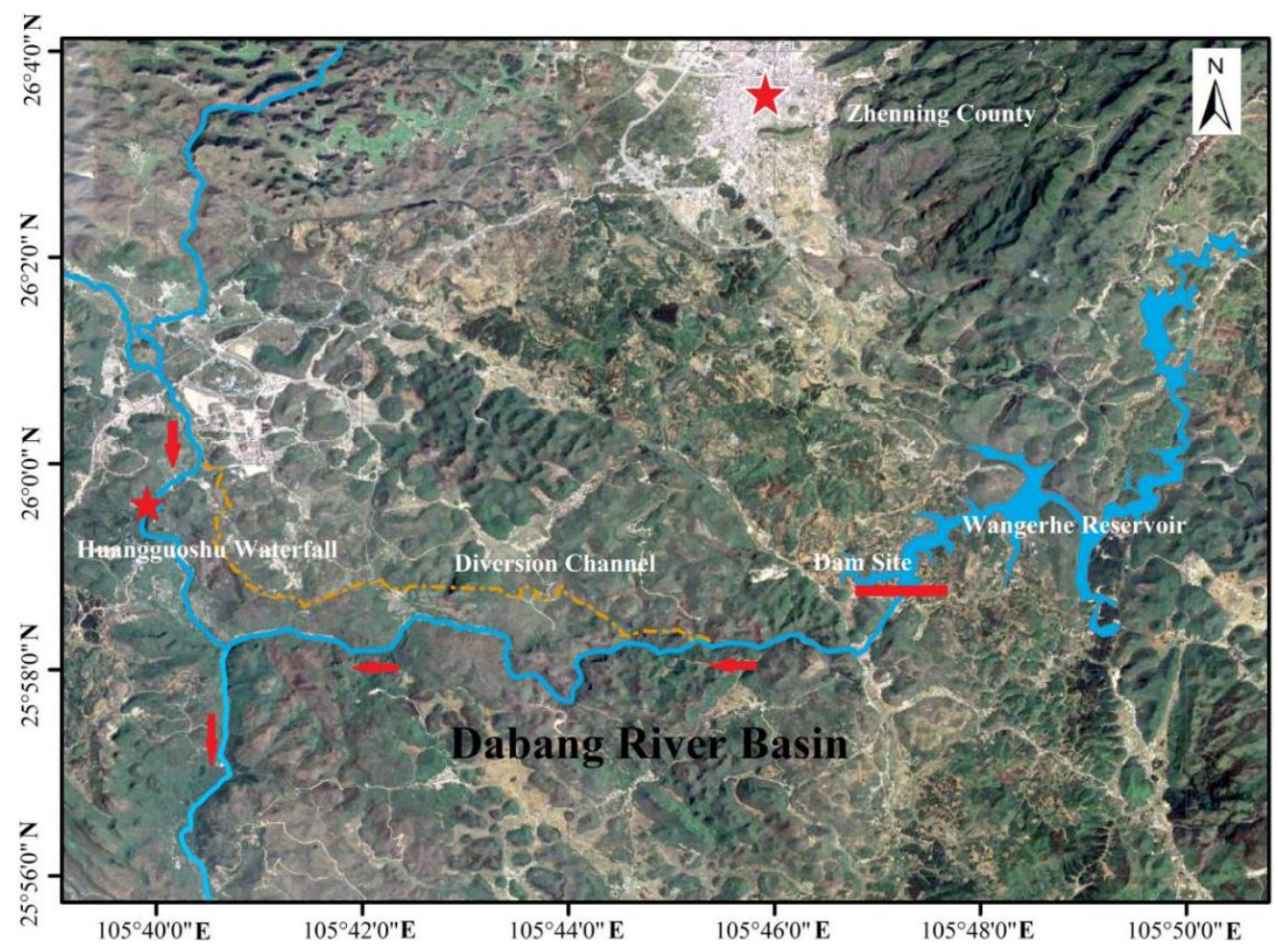

Fig.1. Sketch of Engineering L ocation of Study Area.

The study area is located in the upstream of the largest water source base in China-Yangtze River and Pearl River System, with an average rainfall of more than $1100 \mathrm{~mm}$, rich surface and underground runoff ${ }^{[8]}$. The water resources in the karst area are unevenly distributed, with easily lost surface water and larger groundwater depth. Where the rainfall is mainly

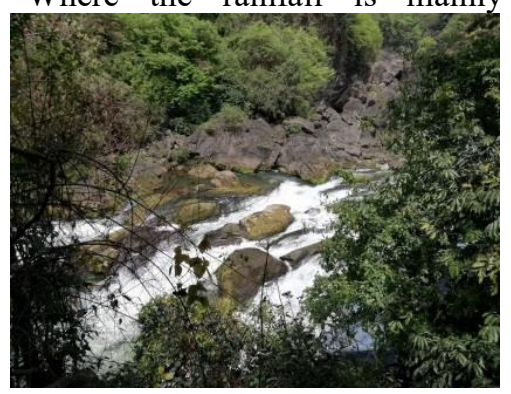

distributed from May to September, accounting for $60 \%-70 \%$ of the whole year, the summer flooding and spring and winter drought are often caused and result in the uneven spatial and temporal distribution of water resources. The karst area has a fragile environment, with exposed rocks (Fig. 2), less vegetation and thin soil layer [9].

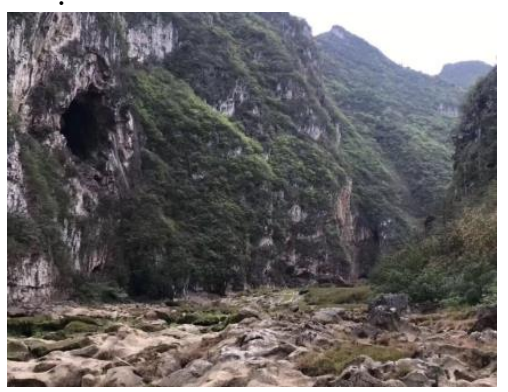

Fig.2. Photographs of Exposed Strata within the basin. 


\section{Ecological Response Characteristics of Interconnected River System Network}

\subsection{Evolution characteristics of the study water system}

Wangerhe reservoir, the water source of the study project, began to be planned in 1998, and began to store water and regulate water when it was completed in 2004. In this paper, we compared the water system connection pattern in different periods in the past 20 years (see in Figure 3) by extracting GIS data of the study area, and analyzed the change characteristics of the connectivity of

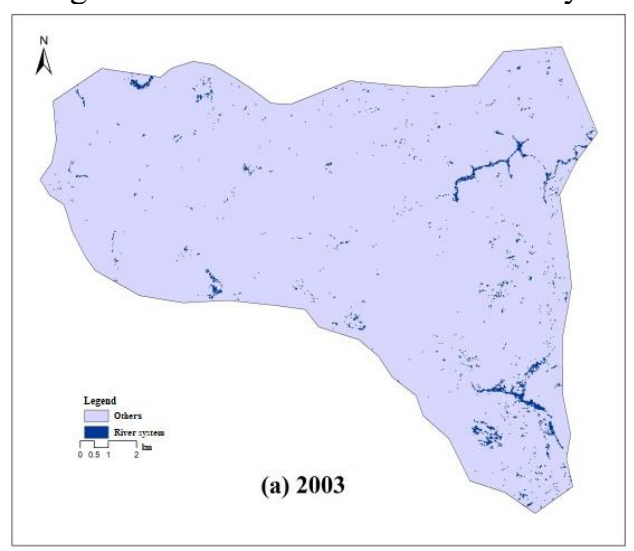

the study water system. Table 1 shows the comparison of water surface area in different periods, it can be seen that there was no significant increase in water surface area during 1998-2003 while the connectivity and the water area is significantly increased after the implementation of the connecting engineering in 2004.

Table 1. W ater Surface Ratio of W atershed

\begin{tabular}{|c|c|c|c|c|c|}
\hline Years & $\mathbf{1 9 9 8}$ & $\mathbf{2 0 0 3}$ & $\mathbf{2 0 0 8}$ & $\mathbf{2 0 1 3}$ & $\mathbf{2 0 1 8}$ \\
\hline $\begin{array}{c}\text { W ater } \\
\text { Surface } \\
\text { Ratio }\end{array}$ & 0.0134 & 0.0153 & 0.0258 & 0.0249 & 0.0260 \\
\hline
\end{tabular}

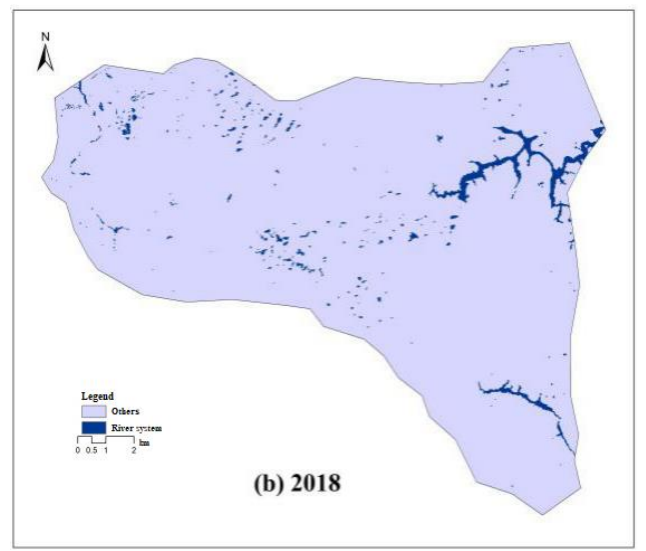

Fig.3. Comparison of watershed area before and after the connection of water system

\subsection{Evolution characteristics of ecological environment in the study area}

In this paper, climate (including rainfall, evaporation, air temperature), hydrology (including water level and flow), terrestrial habitat (vegetation coverage) and water environment (river water quality) are selected as the main indicators to evaluate the ecological environment of the study area. The hydrological and climatic datas from 1998 to 2017 are from Huangguoshu hydrological station.

\subsubsection{Climate}

Figure 4 shows the change rule of 3-year moving average of meteorological data (rainfall, evaporation and temperature) in the study area from 1998 to 2017 based on the moving average method ${ }^{[10]}$. According to the comparison, it can be seen the annual precipitation, evaporation and temperature in the study basin in the past 20 years have decreased slightly in general, while the decline trend of precipitation and temperature is not obvious, showing an irregular fluctuation state. Compared with the changes of temperature and precipitation, the evaporation shows an obvious decreasing trend year by year, and the decreasing range tends to be gentle with the passage of time, which shows that the change of basin connectivity has a certain impact on the regional climate. 
(a) Rainfall (mm)

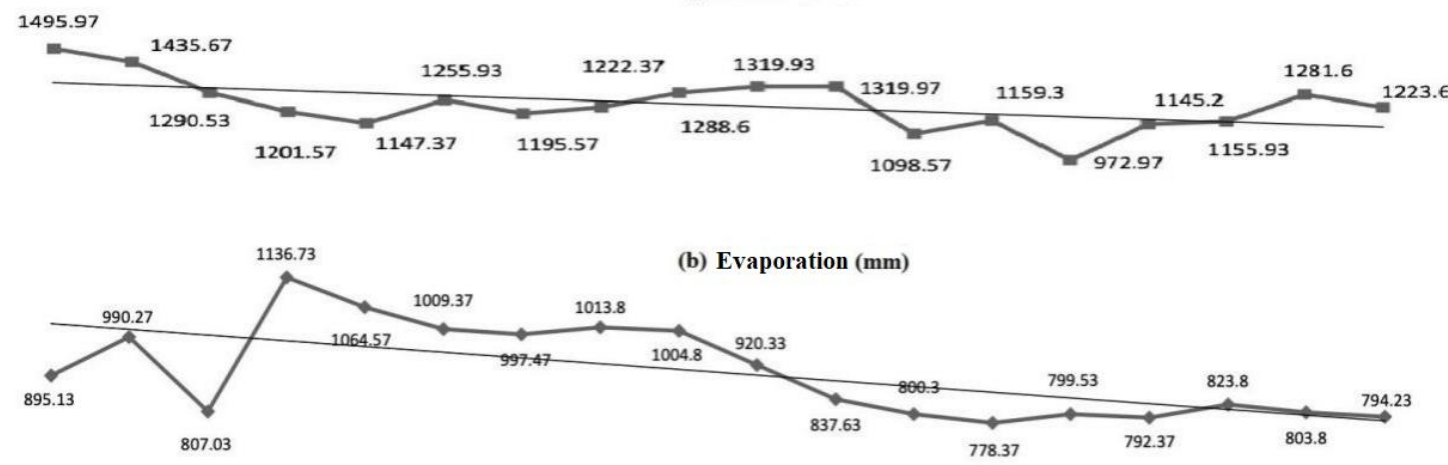

(c) Air temperature ( $\left.{ }^{\circ} \mathrm{C}\right)$

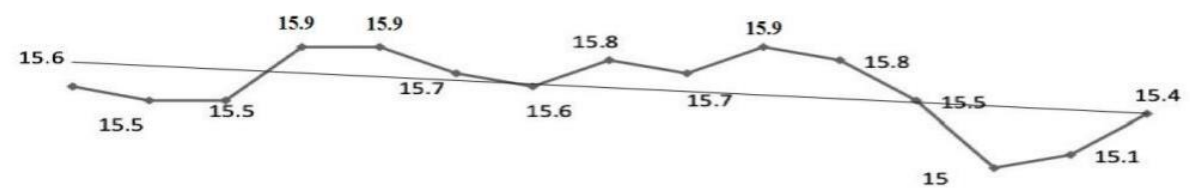

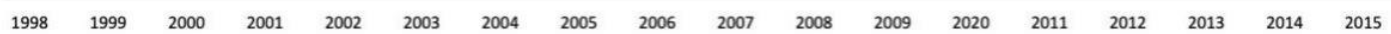

Fig.4. Variation regularity of 3-year moving average of Meteorology Data (Rainfall, Evaporation and Temperature) at Huangguoshu Hydrological Station in 1998-2018

\subsection{Hydrology}

Figure 5 shows the change rule of 3-year moving average of hydrological data (water level and discharge) in the study area from 1998 to 2017, it can be seen the average water level in the upper reaches of Huangguoshu scenic spot has fluctuated up and down irregularly in the past 20 years, and the water level and flow remain stable without obvious change under the influence of the upstream

(a) Water level (m)
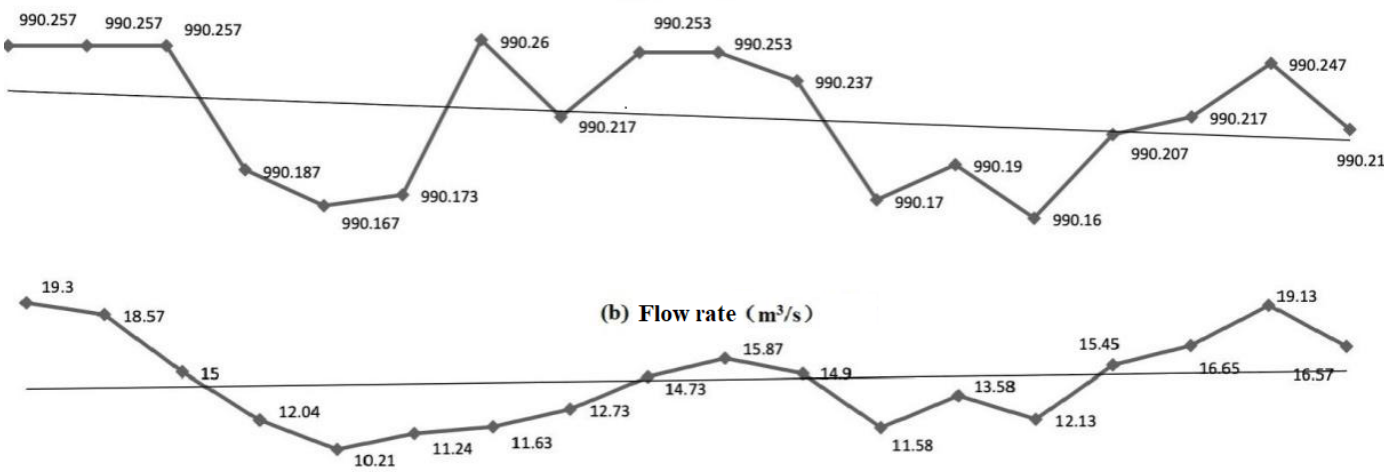

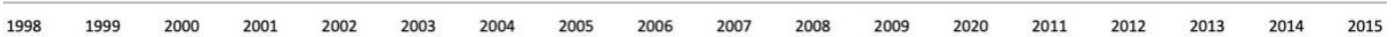

Fig.5. Variation regularity of 3-year moving average of Water level and discharge at Huangguoshu Hydrological Station in 1998-2018.

\subsubsection{Terrestrial landscape}

Vegetation coverage is a key indicator on the scale of terrestrial landscape, which can reflect the change of the regional landscape on a continuous time scale, the impact of the project construction on the surrounding ecosystem of the basin, and the status of the terrestrial habitat and reservoir and the connected project. Which indicates that the change of the basin connectivity has no obvious effect on water level. Since the water system was connected in 2004, the flow of Huangguoshu scenic has increased, and the annual average flow is generally on the rise, which shows that the implementation of the connection project effectively improves the water volume of the receiving area. the terrestrial organisms ${ }^{[11]}$. In this study, vegetation coverage is selected as an important indicator to evaluate the terrestrial habitat of the study area, and the basic satellite remote sensing images of 1998, 2003, 2008, 2013 and 2018 in the study area are retrieved at five-year intervals. The distribution maps of vegetation coverage (Figure 6) are made and NDVI parameters are extracted (Table 2) based on GIS. 

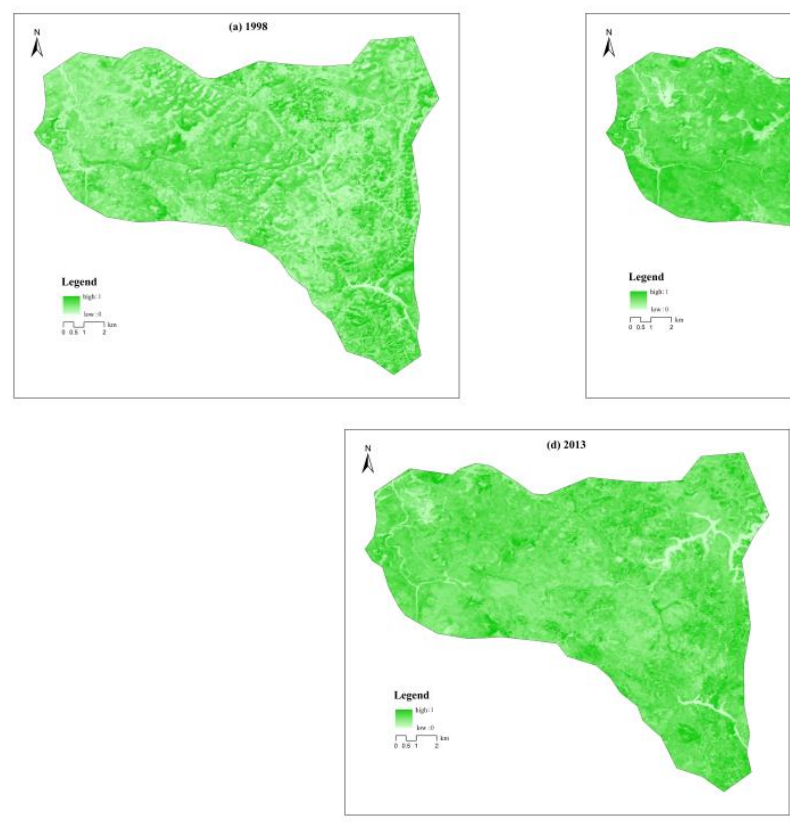

Fig.6. Distribution maps of Vegetation Coverage of the Study Area in Different Years (1998,2003,2008,2013,2018).

Table 2. NDVI parameters in the study area

\begin{tabular}{|c|c|c|c|c|c|}
\hline Years & $\mathbf{1 9 9 8}$ & $\mathbf{2 0 0 3}$ & $\mathbf{2 0 0 8}$ & $\mathbf{2 0 1 3}$ & $\mathbf{2 0 1 8}$ \\
\hline $\begin{array}{c}\text { Maximum } \\
\text { coverage }\end{array}$ & 0.738 & 0.741 & 0.73 & 0.897 & 0.931 \\
\hline $\begin{array}{c}\text { Average } \\
\text { coverage }\end{array}$ & 0.292 & 0.456 & 0.327 & 0.532 & 0.372 \\
\hline $\begin{array}{c}\text { Standard } \\
\text { deviation }\end{array}$ & 0.123 & 0.111 & 0.115 & 0.119 & 0.113 \\
\hline Sum & 52859 & 82770 & 59429 & 96676 & 67730 \\
\hline
\end{tabular}

According to the above maps and NDVI parameters, it can be seen that, after the completion of the Unicom project in 2004, the vegetation coverage in the study area has a significant growth trend, until 2018, the vegetation coverage has significantly increased compared with that 20 years ago. Besides, the terrestrial habitat has greatly improved. With the change of river-lake connectivity, although the vegetation coverage in the region fluctuates up and down, it increases steadily, and the standard deviation is lower than that before the connection, indicating that the vegetation coverage is more and more uniform. This shows that the change of connectivity has a significant impact on the vegetation coverage in the study basin.

\section{(4) Water environment}

Water temperature is the comprehensive thermal effect of solar radiation, long wave effective radiation, heat exchange between water surface and atmosphere, evaporation, hydraulic factors of water body, geological and geomorphic characteristics of water body, water supply source and other factors, etc ${ }^{[12]}$. To a certain extent, the water temperature has an effect on the growth and reproduction of the bacteria and the water self-clarification ability ${ }^{[13]}$. Therefore, water temperature and basic water quality indicators were selected as the important indicators to evaluate the water environment in the study area.

Figure 7 shows the change rule of 3-year moving average of water temperature in the study area from 1998 to 2017 , it can be seen that although the annual water temperature in the basin fluctuates up and down, the change trend of water temperature tends to rise with the passage of time, which indicates the water temperature of the river is obviously affected by the change of the connectivity. Table 3 shows the water quality status and main contaminants of Huangguoshu section in the last four years. It can be seen that the water quality of Huangguoshu is good in recent years. Except for the TP and COD exceeding the grade II water quality standard standard in some periods, water quality condition can basically meet the requirement of the grade II water quality standard in most of the time. 


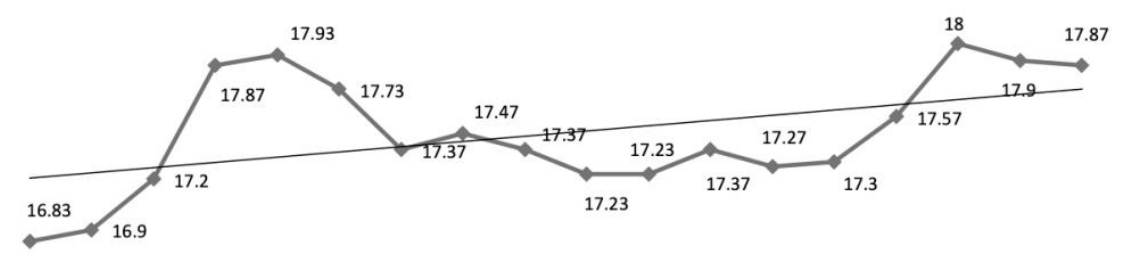

$\begin{array}{llllllllllllllllll}1998 & 1999 & 2000 & 2001 & 2002 & 2003 & 2004 & 2005 & 2006 & 2007 & 2008 & 2009 & 2010 & 2011 & 2012 & 2013 & 2014 & 2015\end{array}$

Fig.7. Three-year moving average of water temperature at Huangguoshu Hydrological Station from 1998 to 2017.

Table 3. Water quality condition and main contaminants exceeding the standard

\begin{tabular}{|c|c|c|c|c|}
\hline \multirow{2}{*}{ Years } & Periods & $\begin{array}{c}\text { Water Quality } \\
\text { Grades }\end{array}$ & $\begin{array}{c}\text { Parameters of super grade I } \\
\text { surface water standard }\end{array}$ & $\begin{array}{c}\text { Parameters of super } \\
\text { grade II surface water } \\
\text { standard }\end{array}$ \\
\hline \multirow{2}{*}{2015} & Dry period & II & DO, NH3-N, TP & - \\
\cline { 2 - 5 } & Flood period & II & CODMn, DO, NH3-N, TP & - \\
\hline \multirow{2}{*}{2016} & Dry period & II & DO, NH3-N, TP & - \\
\cline { 2 - 5 } & Flood period & II & DO, NH3-N, TP, Cr(VI) & - \\
\hline \multirow{2}{*}{2017} & Dry period & II & DO, NH3-N, TP & - \\
\cline { 2 - 5 } & Flood period & II & DO, NH3-N, TP & - \\
\hline \multirow{2}{*}{2018} & Dry period & II & NH3-N, CODMn, TP, Cr(VI) & TP, COD \\
\cline { 2 - 5 } & Flood period & III & DO, NH3-N, CODMn & - \\
\hline
\end{tabular}

\section{Ecological response analysis of river-lake connection}

\subsection{Connectivity and hydro-meteorology}

According to the above analysis, after the implementation of the connecting engineering, the ecological base flow in the water-receiving Area is compensated, the water cycle in the local area is strengthened, and the regional meteorological conditions also are changed. Based on the above data analysis, the evaporation in the study area has a strong response to the change of connectivity, rainfall and temperature have a certain degree of response while are weaker than evaporation. Although there is no obvious change in flow, but it is the basic evaluation index to ensure the ecological basic flow in the basin and play an important role.

\subsection{Connectivity and water quality}

It has been shown that increasing the river-lake connectivity helps to improve the water quality and connectivity of the river, strengthen the water exchange between the transmission and receiving areas, promote the circulation of the water body, and accelerate the dilution and conversion of pollutants in the water ${ }^{[14]}$. Human activities in karst areas are concentrated in the areas where land resources are concentrated and pollution is concentrated, so the concentration of pollutants in the water is diluted to a certain extent after the change of the river-lake connectivity. At the same time, after the long-distance transportation and water conservancy machinery movement and other sufficient oxygen enrichment processes, the oxygen content increases, so that the Water environment capacity will be improved ${ }^{[15]}$. The regeneration cycle is shortened and the water quality is improved. Combined with the above water quality index analysis, after the implementation of the connecting project, the water quality in the dry season can reach the grade II water quality level. To some extent, water quality is affected by the basin connectivity.

\subsection{Connectivity and terrestrial habitat}

The change of river-lake connectivity will affects the distribution of biological communities. At the same time, the status of biological communities is to some extent the embodiment of connectivity ${ }^{[16]}$. After changing the river-lake connectivity, the river morphology will change to a certain extent, and the biodiversity will also change. The paper analyzes the change of vegetation coverage and water surface area before and after the connection of water system, and the results show that the water surface area and the vegetation coverage will increase gradually after changing the water system connectivity, which has a high degree of response.

\subsection{Connectivity and social economy}

Increasing the connection of water system can also expand the water area, increase the length of the river, and form ecological landscapes such as lakes and waterfalls. The water diversion project will lead the reservoir water of Wanger River to the upstream of Huangguoshu waterfall, supplement the flow of Huangguoshu waterfall in the dry season, improve the water landscape, and promote the local tourism economy. At the same time, the allocation of water resources also 
ensure the demand of water resources in the water receiving area. In addition, the development of local industry and agriculture can be greatly promoted by improving the connectivity of river- lake water system and regulating the distribution of water resources.

\section{Result}

Taking the Huangguoshu Waterfall-Wangerhe reservoir connection engineering in Dabang River Basin of Guizhou Province as an example, this paper collects the basic data of hydrometeorology, vegetation coverage and river water quality in the Dabang River Basin in the past 20 years, and study and analysis the connectivity of water system and the ecological factors based on GIS which including meteorological, terrestrial habitat and water environment before and after the completion of the Link Project. The research shows that the implementation of the connectivity project can greatly improve the connectivity of river-lake water systems, and the change has a significant impact on the hydrology, meteorology, terrestrial habitat and water environment of the basin, which is specifically reflected in the increase of connectivity, resulting in the regional rainfall, evaporation and temperature decreasing year by year, while the vegetation coverage is increasing year by year, indicating that the terrestrial habitat gradually improved with the increase of the connectivity. In addition, after the implementation of the river-lake connection project, the water quality in the receiving area is also good, which does not bring water pollution risk to the receiving area.

\section{Acknowledgements}

This research is supported by the Special Foundation of the Water Conservancy Bureau of Guizhou Province (Grant No. KT201712) and Young talents project of Guizhou Provincial Department of Education (Grant No. KY [2017] 120).

\section{Reference}

1. Wang zhong-gen, Li zong-li, Liu Chang-ming, et al. Discussion on Water Cycle Mechanism of Interconnected River System Network[J]. Journal Of Natural Recources, 3: 523-529 (2011)

2. Li yuan-yuan, Huang huo-jian, Li zhong-li, et al. Practical Experience and Development Trend of the Interconnected River System Network[J]. South to North Water Transfers and Water Science Technology,12(04):81-85 (2014)

3. Dong zhe-ren.. River Ecological Restoration, M, (2013)

4. Zhao jin-yong, Dong zhe-ren, Zhai zheng-li, et al. Evaluation Method for River Floodplain System Connectivity based on Graphic Theory[J]. Journal of Hydraulic Engineering, 39(5):537-543(2011)
5. Feng shun-xin, Li hai-ying, Li chong, Wang jun-na. Study on the impact evaluation indicator system of River and Lake System Interconnection I: impact evaluation indicator system and evaluation method[J]. Journal of China Institute of Water Resources and Hydropower Research,12(04):386-393(2014)

6. Sheng mao-ying, Liu yang, Xiong kang-ning. Response of soil Physical-chemical properties to rocky desertification succession in South China Karst. Acta Ecologica Sinica, 33(19):6303-6313(2013)

7. Yang ming-de. Hydro-geomorphological System of Karst Basin[M], (1998)

8. Liu li-ying, Yang qing-wei, Zeng yi-xiao, He xiu-juan, Guan dong-jie. Construction and Application of Water Resource Security Evaluation Model in Karst Area: A case study of Guizhou Province $[\mathrm{J}]$. Sinica,37(02):203-210(2018)

9. Fan fei-de, Wang ke-lin, Xuan yong, Yue yue-min. Eco-environmental Sensitivity and its Spatial Distribution in Karst Regions, Southwest China[J]. Resources and Environment in the Yangtze Basin,20(11):1394-1399 (2011)

10. Ji ben-hao. Development of Data Collector and Its Data Processing Methods in Marine Environment[D]. China University of Petroleum (2009)

11. Ma shi-bin, An yu-lun, Yang guang-bin. Analysis of Vegetable NDVI Variation on Various Lithology in Karst Area Based on GIS[J]. Research of Soil and Water Conservation,24(02):202-206+212 (2017)

12. Wang qiu-shun, Li zhi-yong. Numerical simulation of water temperature under diurnal variation of air temperature in the Hangzhou Bay[J]. Marine Science Bulletin, 37(3):303-309 (2018)

13. Zhang shi-kun, Zhang jian-jun, Tian yi-ling, et al. Study on self purification and degradation of typical pollutants in Huayuankou of the Yellow River[J].Yellow River, 28(4):46-47 (2006).

14. Zhang jun. Analysis of water carrying capacity in Taian City based on the Connection of Rivers and Lakes[D]. China Institute of Water Resources and Hydropower Research (2013)

15. Xiang ying, Wei an-lei, Ru tong, Yang xiao-gang. Rivers System Connection and Regional Ecological and Environmental Impacts in China[J].China's Population, Resources and Environment, 25(S1):139-142 (2015)

16. Xia jun, Gao yang, Zuo qi-ting, Liu xiao-jie, Chen qing-mei, Dou ming. Characteristics of Interconnected River System and its Ecological Effects on Water Environment[J]. Progress in Geography, 31(01):26-31 (2012). 